the international English-speaking psychiatric community actively participated in the conference. Or, the selection of papers is unbiased and constitutes a truly representative sample of the contributors. Perhaps the truth lies on a continuum between the two tending towards the latter. Evidence to support this is provided by the membership of the organising committee who are also the editors of the Supplement, all five women are from the Institute or the Maudsley. The fact that two further conferences have been held at the Institute suggest lessons have not been learnt and that this trend is likely to continue.

It is important to acknowledge the achievements of the organisers in organising conferences, stimulating "yet more discussion and research", in an important but neglected subject. I hope that in future attempts are made to encourage active participation from outside the widely acknowledged "centre of excellence". Changing the venue for the third conference may be a step in the right direction.

\section{Mapperley Hospital}

O. JuNAID

\section{Nottingham NG3 6AA}

DEAR SIRS

We welcome the interest with which Dr Junaid has examined the supplement from our conference. We support the notion that such conferences could be organised elsewhere in other "centres of excellence" and we, in fact, would encourage this. Five international speakers were invited, but were unable to attend and four out of the 11 speakers came from the Institute of Psychiatry. All speakers were, of course, asked to contribute to a conference publication. As Dr Junaid is no doubt aware, speakers are not always eager to transfer lectures into publications. The Supplement contains some of the conference material, along with papers from others working in the field. Two subsequent conferences were organised by other colleagues at the Institute, and again, had good national and international representation among speakers and audience. We hope Dr Junaid's suggestions are noted and that further conferences on the topic are organised at other venues and we would support anyone doing so.

We feel there is a danger in emphasising the geographical origin of the papers in our supplement rather than evaluating their content and quality.

THE EDITORS

WOMEN AND MENTAL HEALTH SUPPLEMENT
Institute of Psychiatry
London SE5 $8 A F$

\section{Clozapine and Part IV of the Mental Health Act 1983 \\ DeAR Sirs}

The Mental Health Act Commission understands that clozapine (Clozaril, Sandoz) is being increas- ingly used for the treatment of some in-patients with schizophrenia resistant to other treatments. Clozapine is being given to some detained patients whose consent to treatment has been certified by the RMO under Section 58 of the Mental Health Act 1983 on Form 38, and some who are not consenting, whose treatment is authorised by a doctor appointed under Part IV of the Act (on Form 39). It is accepted that this treatment necessarily involves regular haematological screening, initially on a weekly basis. There may be occasions when the patient will agree to take the tablets but will not agree to the necessary monitoring. The position is similar in principle to that involved in lithium treatment. The steps to be taken to secure the blood samples and the likely effect on the patient of this procedure has to be considered by the RMO in recommending the treatment, by the clinical team administering the treatment, as well as the Section 58 Approved Doctor when the treatment falls within the provisions of Part IV of the Act.

In describing drug treatment regulated by the Consent to Treatment provisions, the Code of Practice (paragraph 16.11) states that "the RMO should indicate on the certificate the drugs proposed by the classes described in the British National Formulary". Clozapine is an anti-psychotic drug (BNF 4.2.1). In view of the special conditions attached to treatment with clozapine, the Commission recommends that some modification of this guidance is now necessary. Specifically, when the patient is certified as consenting by the RMO on Form 38 and the treatment includes clozapine, this should be explicitly stated on the certificate by adding "including clozapine" to the description "anti-psychotic drugs, BNF 4.2.1". The same guidance is being given to Section 58 Approved Doctors in relation to Form 39 .

The Commission has responsibility for keeping under review the implementation of the Code of Practice and for making recommendations to the Secretary of State as to possible changes and this guidance will be incorporated in these recommendations in due course.

\section{Mental Health Act Commission \\ Maid Marian House \\ 56 Houndsgate}

Nottingham NG1 6BG

\section{Use of clozapine \\ DEAR SIRS}

We read with interest Launer's account of his experience with clozapine (Psychiatric Bulletin, April 1991, 15, 223-224).

Cook et al (1988) have identified the problems of recruitment into clinical trials. Similar problems beset us as we identified three patients who had 